\title{
Update of Cultivated Land Quality Grade Based on GIS-A Case Study of a County in Guangxi
}

\author{
Yuening Song, Xiangwen Cai*, Mi Tang, Yan Zhao, Mingyuan Liu \\ Guilin University of Technology, Guilin, China \\ Email:1315643664@qq.com, *598196224@qq.com
}

How to cite this paper: Song, Y.N., Cai, X.W., Tang, M., Zhao, Y. and Liu, M.Y. (2019) Update of Cultivated Land Quality Grade Based on GIS-A Case Study of a County in Guangxi. Open Journal of Soil Science, 9, 243-254.

https://doi.org/10.4236/ojss.2019.912015

Received: November 1, 2019

Accepted: December 13, 2019

Published: December 16, 2019

Copyright $\odot 2019$ by author(s) and Scientific Research Publishing Inc. This work is licensed under the Creative Commons Attribution International License (CC BY 4.0).

http://creativecommons.org/licenses/by/4.0/

(c) (i) Open Access

\begin{abstract}
The quality of cultivated land has an important influence on agricultural output, food security, sustainable development and the ability of using cultivated land resources. As the trend of cultivated land quality is getting more and more attention, in order to strengthen the management of cultivated land quality, improve the precision of cultivated land quality and other achievements, and maintain the current situation of cultivated land quality and other achievements. For this paper, taking A county of Guangxi Zhuang Autonomous Region as an example, with the support of GIS, the paper studies the grade and grade renewal of cultivated land by using the superposition method, studies the grade and grade change of regional cultivated land and its spatial distribution, grasps the status quo change of cultivated land and the grade and grade change of cultivated land caused by the quality construction of cultivated land in the year, and then provides scientific data for land use plan, land consolidation and cultivates land protection.
\end{abstract}

\section{Keywords}

Cultivated Land Quality, Grade Renewal, GIS, A County, Guangxi

\section{Introduction}

The old proverb "the barn is solid and the world is safe" gives an image interpretation to the value of grain. Grain, at all times, is the foundation of national government and national security. Cultivated land is the key foundation and guarantee of food production. The latter cannot exist independently of the former, and cultivated land is the "hotbed". The premise and guarantee of human survival lies in cultivated land. The sustainable development of our country depends on the protection of cultivated land. Nowadays, the most critical research 
project is to explore measures to protect cultivated land and promote the comprehensive productivity of food, so as to fully guarantee the national food security [1]. Therefore, the scientific evaluation of cultivated land quality is helpful to optimize the allocation and sustainable utilization of land resources, maintain the dynamic balance of total cultivated land, and realize the sustainable development of China \& APOS, economy and society to a certain extent. The continuous improvement of cultivated land quality level can greatly promote the land management in China to change from quantitative type to qualitative type as soon as possible, and realize the unity of ecological management and protection as soon as possible, and in addition, in order to implement the farmland occupation compensation mechanism, achieve the goal of regional farmland occupation compensation coordination, farmland transfer, farmland productivity evaluation and basic farmland non-destructive to give strong guidance [2].

\section{Regional Overview}

County A is under the jurisdiction of Liuzhou City, which is located in the southeast of Guangxi Zhuang Autonomous Region. In latitude and longitude, it is in the range of $108^{\circ} 50 \mathrm{E}$ to $109^{\circ} 36^{\prime} 19^{\prime} \mathrm{E}, 24^{\circ} 26^{\prime} 4^{\prime} \mathrm{N}$ to $24^{\circ} 50^{\prime} 17^{\prime} \mathrm{N}$. To the East is Luzhai County, to the West are Luocheng county and Yishan county (now Yizhou city), to the south are Liujiang county and Liuzhou City, and to the north are Rongshui county and Rongan county. In terms of climate characteristics, this area has subtropical monsoon climate, with sufficient illumination throughout the year, suitable temperature in summer, low temperature in winter and abundant water resources. Multi-year average temperature is $20.2^{\circ} \mathrm{C}$, January is the coldest, monthly average temperature is $9.9^{\circ} \mathrm{C}$; the monthly average temperature of July is $28.5^{\circ} \mathrm{C}$, the annual average number of days is 155.7 days, and the annual average rainfall is $1340.2 \mathrm{~mm}$. The rainy season is concentrated in the main flood season of Liucheng County from May to July [3]. This is a semi hilly area with low Karst mountains crisscrossing in the low hills and valleys.

\section{Research Data and Methods}

\subsection{Data Source and Processing}

\subsubsection{Data Collation}

The data used by the research institute is from the updated data of cultivated land quality at county level in 2016, which is accepted and approved by the Ministry of land and resources. Data types include maps, reports, tables, and databases. According to the collected data, according to the farmland grading system of Guangxi, determine the designated crop light temperature/climate potential index, farmland quality grading evaluation factor index, evaluation index weight, yield ratio coefficient, land use coefficient and land economic coefficient of the county where the project is located. 


\subsubsection{Make and Update the Working Base Map of Evaluation}

In order to facilitate the data analysis and result unification, this study first completed the SHP format transformation from land remediation project map to ArcGIS with the help of ArcGIS 10.2 platform. ArcGIS is used to supplement and modify errors and missing attributes during data format conversion. The data coordinate system is unified, and the corresponding registration processing is completed for the spatial position [4]. According to the evaluation of cultivated land quality, the corresponding base map can be made by two ways: superposition and incremental data packet extraction. According to the collected data, county A of Guangxi chooses to adopt the superposition method, use the ArcGIS platform and use the superposition method to operate. First, sort out and accept the 2016 project data: land consolidation project, farmland water conservancy construction project, agricultural comprehensive development project, and then put the area and area information of these projects into the cultivated land quality construction layer. Then the overlay of the construction layer to the land change survey type layer is carried out. Finally, the overlapping cultivated land spots in the project area distribution of the same cultivated land quality construction layer are extracted.

The base map is divided into two layers, one is the annual renewal evaluation layer of cultivated land map spot; the other is the annual renewal evaluation layer of sporadic cultivated land.

When acquiring the cultivated land map points within the high-quality construction scope, the extraction steps are implemented for the overlapping cultivated land map points. The principle is that when some map points fall within the cultivated land quality construction project area and some fall outside the cultivated land quality construction project area, the whole map points are taken as the partial implementation extraction of the annual update benchmark map. Add/reduce cultivated land patches and high-quality construction cultivated land patches into the base map of annual renewal evaluation [5]. To complete the combination of the above plaques, two identical map points can be seen in the same part. These two points are quality construction points, new map points and reduced map points at the same time. Then, the map points of cultivated land quality construction are removed and marked as reduced/new map points.

\subsubsection{Generate Annual Update Data Package of Cultivated Land Quality}

The evaluation results of the annual renewal of the relevant cultivated map spots are sorted out, and the corresponding "submission requirements" of the results are used as a reference to generate the corresponding annual renewal data package. The layer of cultivated land (including scattered cultivated land) in the land use database, the county level/scattered classification unit in the previous year \& apos; s level database, and the updated data package compiled in this year are superposed, so as to complete the construction of the annual level database of cultivated land quality. 


\subsection{Grade Determination and Conversion}

In view of the cultivated land quality and other achievements in this area, Guangxi Zhuang Autonomous Region has issued the corresponding "supplementary and perfect work implementation plan". Under the guidance of this plan, around the quality evaluation work of new cultivated land and quality construction cultivated land, we first extract the map spots of these two types of cultivated land, and then obtain the relevant attribute data through the project data and field supplementary survey, and then use the above-mentioned data to under the guidance of the regulations of farmland quality classification [6] mentioned above, the quality of the above two types of cultivated land is evaluated. Based on the cultivated land layers of land remediation project, annual land use adjustment map, farmland water conservancy construction and agricultural comprehensive development, the field investigation is carried out on the information of relevant factors of each quality construction and new cultivated map spots, such factors include soil thickness, soil erosion status, surface soil texture, soil salinization status, distance between barrier layer and surface, drainage Water condition, soil nutrient condition, irrigation water quality, soil organic matter level, irrigation assurance rate, soil $\mathrm{pH}$, etc., and then quantize the data of grading factors [7] [8] [9].

According to the regulations of classification of agricultural land quality (GB/T28407-2012) [6], the index and classification parameter system of cultivated land quality are updated, the index of natural quality, the index of utilization at the autonomous region level and the index of economy at the autonomous region level are calculated [10] [11]. Then, the classification of cultivated land quality at the autonomous region level is divided according to the index of nature, the index of utilization, the index of economy, the index of utilization, and so on. Among them, the first grade has the worst quality. Finally, the evaluation results of cultivated land quality in the autonomous region are converted into national cultivated land quality.

a) The rules for the conversion of autonomous district-level indices to national-level indices are as follows:

National Natural Quality Index $=$ Autonomous Natural Quality Index $\times$ $1.0188+695.08$

National utilization index $=$ autonomous utilization index $\times 0.5776+616.86$

National economic equality index $=$ autonomous district economic equality index $\times 0.6558+696.6$

b) The new national grade of cultivated land is divided according to the new national grade of cultivated land by equal distance method [6] according to the new national grade of cultivated land. The distance between the national grade of cultivated land is $400,0-400$ is $15,400-800$ is 14 , etc. $\geq 5600$ is 1 ; the distance between national utilization class and economic class is $200,0-200$ is 15 , 200 - 400 is 14 , etc. 2800 - 3000 is 1 grade (best quality). 


\section{Evaluation Results of Cultivated Land Quality in a County of Guangxi}

\subsection{General Situation of Cultivated Land Quality}

\subsubsection{Grade Results of Cultivated Land Quality in a County, Guangxi}

According to the summary of 2016 evaluation results of cultivated land quality level in county A of Guangxi, it can be seen from Table 1 and Figure 1 that the area of national natural quality grade higher land in county A of Guangxi is $24,297.71$ hectares, accounting for $31.33 \%$ of the total cultivated land in the whole county, $53,245.68$ hectares of medium land, $68.67 \%$ of the total cultivated land in the whole county, 24,323.28 hectares of national grade higher land, $31.37 \%$ of the total cultivated land in the whole county, 53,220.11 hectares of medium land, $68.63 \%$ of the total cultivated land in the whole county, 192.31 hectares of national economic grade land, $0.25 \%$ of the total cultivated land in the whole county, $43,764.92$ hectares of high land, $56.44 \%$ of the total cultivated land in the whole county, and $33,586.15$ hectares of medium land $43.31 \%$ of the total cultivated land. Figure 1 shows the distribution of natural quality, utilization and economy at the national level.

\subsubsection{Distribution Characteristics and Law of National Natural Quality of Cultivated Land in a County of Guangxi}

Based on the updated database of cultivated land quality in the region and generating Figure 2, the national natural quality of cultivated land in county A of Guangxi is distributed between 5 and 11 grades according to the statistics of the natural quality of each township. Among them, 11 grades correspond to the

Table 1. Summary of cultivated land quality assessment results in county A of Guangxi.

Area: $\mathrm{Ha}$

\begin{tabular}{|c|c|c|c|c|c|c|}
\hline \multirow{2}{*}{ category } & \multicolumn{2}{|c|}{$\begin{array}{l}\text { National natural } \\
\text { quality grade }\end{array}$} & \multicolumn{2}{|c|}{ National utilization grade } & \multicolumn{2}{|c|}{ National economy grade } \\
\hline & $\begin{array}{c}\text { The measure } \\
\text { of area }\end{array}$ & Percentage & $\begin{array}{c}\text { The measure } \\
\text { of area }\end{array}$ & Percentage & $\begin{array}{c}\text { The measure } \\
\text { of area }\end{array}$ & Percentage \\
\hline 4 etc. & 0.00 & $0 \%$ & 0.00 & $0 \%$ & 192.31 & $0.25 \%$ \\
\hline Classy & 0.00 & $0 \%$ & 0.00 & $0 \%$ & 192.31 & $0.25 \%$ \\
\hline 5 etc. & 2232.30 & $2.88 \%$ & 1131.07 & $1.46 \%$ & 1958.97 & $2.53 \%$ \\
\hline 6 etc. & $17,710.42$ & $22.84 \%$ & $12,489.56$ & $16.11 \%$ & 4780.90 & $6.17 \%$ \\
\hline 7 etc. & 4354.99 & $5.62 \%$ & 9948.28 & $12.83 \%$ & $11,920.32$ & $15.37 \%$ \\
\hline 8 etc. & 0.00 & $0 \%$ & 754.37 & $0.97 \%$ & $25,104.74$ & $32.38 \%$ \\
\hline $\begin{array}{l}\text { Higher } \\
\text { ground }\end{array}$ & $24,297.71$ & $31.33 \%$ & 24323.28 & $31.37 \%$ & 43764.92 & $56.44 \%$ \\
\hline 9 etc. & 8896.26 & $11.47 \%$ & $33,141.81$ & $42.74 \%$ & $23,410.60$ & $30.19 \%$ \\
\hline 10 etc. & $42,755.06$ & $55.14 \%$ & $20,078.30$ & $25.89 \%$ & $10,175.55$ & $13.12 \%$ \\
\hline 11 etc. & 1594.36 & $2.06 \%$ & 0.00 & $0 \%$ & 0.00 & $0 \%$ \\
\hline Moderately & $53,245.68$ & $68.67 \%$ & $53,220.11$ & $68.63 \%$ & $33,586.15$ & $43.31 \%$ \\
\hline Total & $77,543.39$ & $100 \%$ & $77,543.39$ & $100 \%$ & $77,543.39$ & $100 \%$ \\
\hline
\end{tabular}



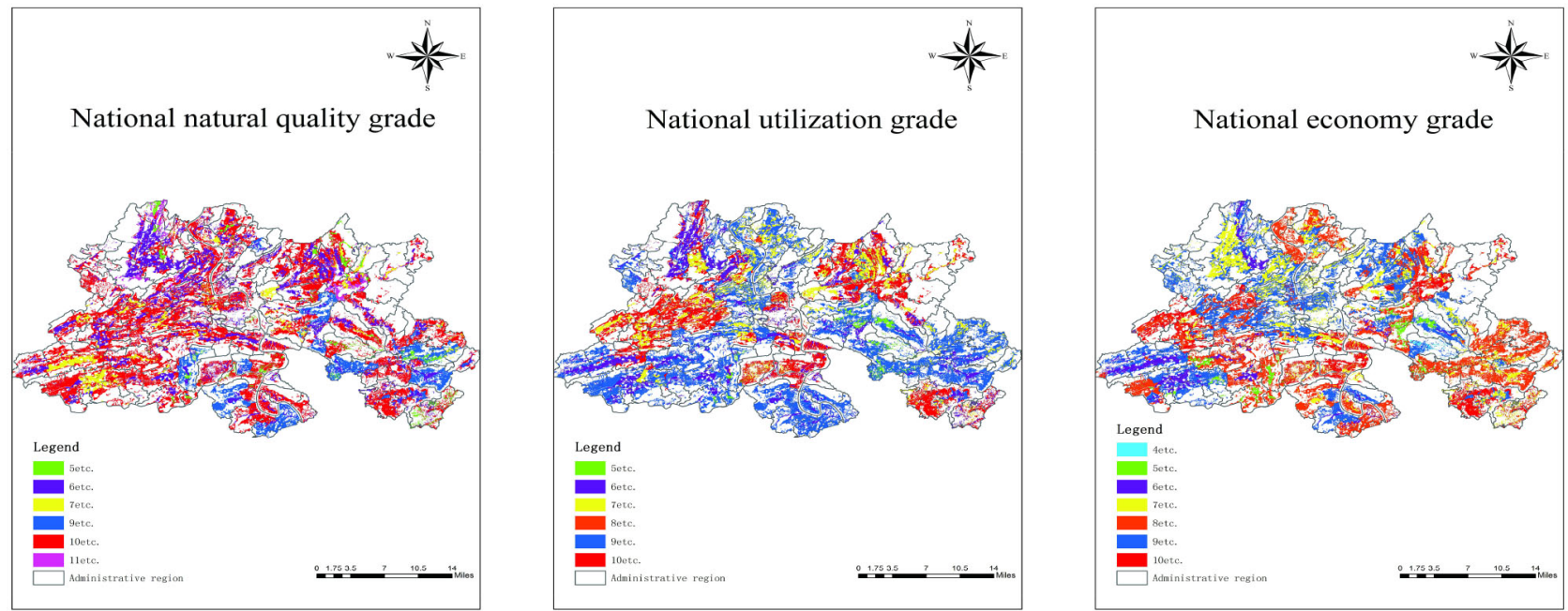

Figure 1. Distribution of cultivated land quality in a county, Guangxi.
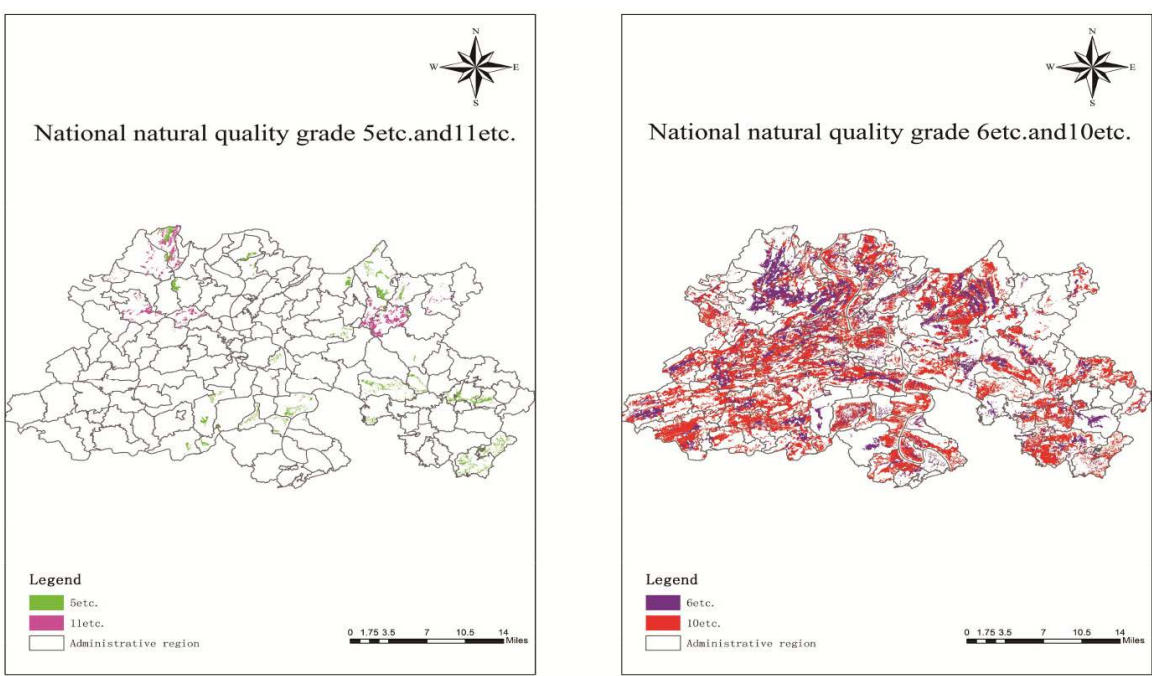

Figure 2. Distribution characteristics and rules of national natural quality of cultivated land in a county, Guangxi.

lowest natural quality grade, which covers an area of 1594.36 hectares, accounting for $2.06 \%$ of the total cultivated land in the whole county. They are distributed in Guzhai Township, Taiping Town and Zhailong town the highest natural quality grade is 5, covering an area of 2232.30 hectares, accounting for $2.88 \%$ of the total cultivated land area of the county, mainly distributed in Guzhai Township, Dongquan town and Taiping town; the natural quality grade 6 and grade 10 cultivated land are most distributed, covering an area of 60,465.48 hectares, accounting for $77.98 \%$ of the total cultivated land area of the county, mainly including Taiping Town, Guzhai Township and Dapu town.

\subsubsection{The Distribution Characteristics and Law of Cultivated Land at National Level in a County of Guangxi}

According to the updated cultivated land quality database of this region, Figure 3 is generated, and the national land use grade divided by township is counted, 

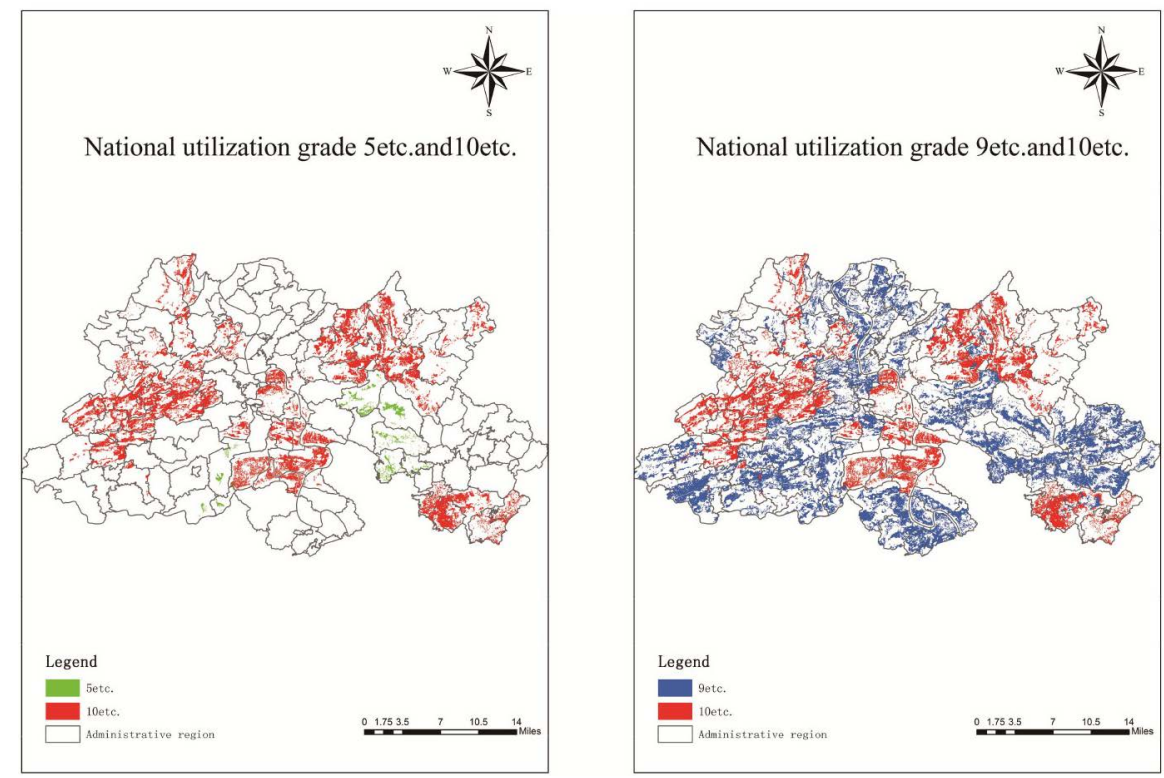

Figure 3. Distribution characteristics and rules of cultivated land at national level in A county, Guangxi.

the national utilization grades of cultivated land in county A of Guangxi are distributed between 5 and 10, among which the lowest utilization grade is 10 , covering an area of $20,078.30$ hectares, accounting for $25.89 \%$ of the total cultivated land area in the whole county, mainly distributed in Fengshan Town, Zhailong town and Taiping town; the highest utilization grade is 5Etc., covering an area of 1131.07 hectares, accounting for $1.46 \%$ of the total cultivated land area of the county. The areas involved are mainly Shapu Town, Liutang town and Mashan township. The cultivated land of grade 9 and grade 10 is the most widely used, covering an area of 53,220.11 hectares, accounting for $68.63 \%$ of the total cultivated land area of the county, mainly distributed in Dapu Town, Dongquan town and Taiping town.

\subsubsection{The Distribution Characteristics and Law of the National Economy of Cultivated Land in a County of Guangxi}

According to the updated database of cultivated land quality in this region, Figure 4 is generated and the statistical data of township national economy is obtained, it can be seen that the national economy of cultivated land in county A of Guangxi is distributed between 4 and 10, among which the lowest economy is 10 , covering an area of $10,175.55$ hectares, accounting for $13.12 \%$ of the total cultivated land area in the whole county, and the involved areas are mainly Fengshan Town, Dongquan town and Chongmai town; the highest one is Fengshan Town, Dongquan town and Chongmai town The economic grade is 4 , covering an area of 192.31 hectares, accounting for $0.25 \%$ of the total arable land area of the county, which is all distributed in Shapu town; the economic grade 8 and 9 are the most distributed, covering an area of 48,515.34 hectares, accounting for $62.57 \%$ of the total arable land area of the county, and the areas involved are mainly Taiping Town, Dongquan town and Dapu town. 

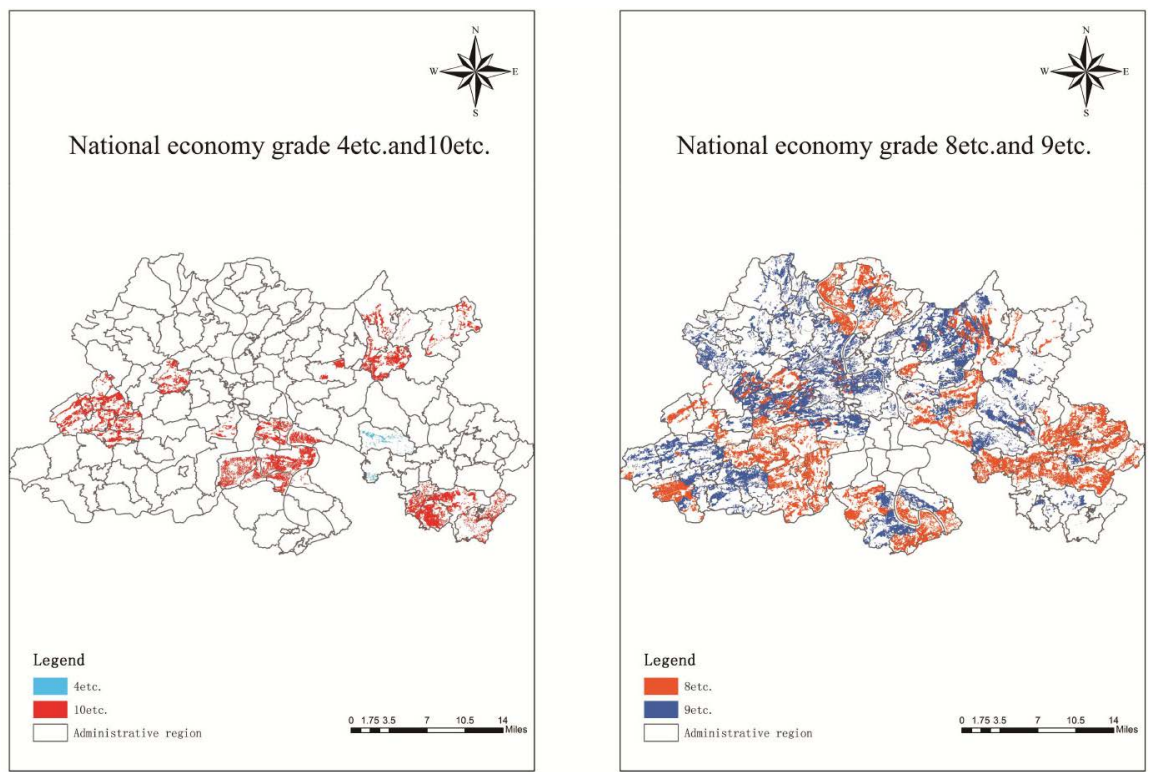

Figure 4. Distribution characteristics and rules of national economic grade of cultivated land in A county, Guangxi.

\subsection{Analysis on the Change of Cultivated Land Quality in a County of Guangxi}

\subsubsection{Analysis of New Cultivated Land in a County of Guangxi}

According to the change data of land use status in 2016, there was no new cultivated land in county A of Guangxi.

\subsubsection{Quality Grade of Cultivated Land Reduction in a County, Guangxi}

According to Table 2, in 2016, the area of cultivated land was reduced by 41.80 hectares in County A of Guangxi, in which 36.60 hectares of dry land, 4.84 hectares of paddy land and 0.36 hectares of watered land were occupied, the corresponding proportion was $87.56 \%, 11.59 \%$ and $0.86 \%$ respectively. The main reasons for the decrease of cultivated land in County A of Guangxi are highway land, hydraulic construction land, facilities agricultural land, town, village, scenic spot and special land occupation. 0.03 hectares $(0.1 \%)$ of cultivated land was reduced due to hydraulic construction land; 2.18 hectares, or 5.2 per cent, of farmland reduced due to agricultural facilities; The cultivated land reduced by the towns was 22.77 hectares, or 54.5 per cent; 0.92 hectares, or 2.2 per cent, of cultivated land reduced due to villages; 11.25 hectares (26.9 per cent) of cultivated land was reduced due to scenic spots and special land. The cultivated land was reduced in all villages and towns, which was most distributed in Tai Po Town and Feng Shan Town, with an area of 30.74 hectares ( 73 hectares), 53 per cent.

\subsubsection{Quality Construction of Cultivated Land in a County of Guangxi}

In 2016, 16 high standard basic agricultural projects were completed and accepted, including "land renovation project of high quality and high yield sugar cane base in Gongshantun, Zhitong village, Chongmai Town, Liucheng county", 
Table 2. Annual renewal of cultivated land quality and reduction of cultivated land flow in county A of Guangxi.

Area: $\mathrm{Ha}$

\begin{tabular}{|c|c|c|c|c|c|c|c|}
\hline $\begin{array}{c}\text { Current } \\
\text { situation class } \\
\text { Autochthonous }\end{array}$ & $\begin{array}{c}\text { Highway } \\
\text { land }\end{array}$ & $\begin{array}{c}\text { Land for } \\
\text { hydraulic } \\
\text { construction }\end{array}$ & $\begin{array}{c}\text { Facility } \\
\text { agricultural } \\
\text { land }\end{array}$ & $\begin{array}{c}\text { organic } \\
\text { town }\end{array}$ & Village & $\begin{array}{c}\text { Scenic spots } \\
\text { and special } \\
\text { land }\end{array}$ & Total \\
\hline dry land & 3.71 & 0.03 & 1.60 & 20.49 & .68 & 10.10 & 36.60 \\
\hline Irrigated land & - & - & 0.36 & - & - & - & 0.36 \\
\hline paddy field & 0.94 & - & 0.23 & 2.29 & 0.24 & 1.15 & 4.84 \\
\hline Total & 4.65 & 0.03 & 2.18 & 22.77 & 0.92 & 11.25 & 41.80 \\
\hline
\end{tabular}

"land renovation project of high quality and high yield sugar cane demonstration base in Sifatun, Sixiang village, Guzhai Township, Liucheng county (2014)”, with a construction scale of about 909.46 hectares.

There are 909.46 hectares of cultivated land affected by the implementation of the project, including 267.77 hectares of paddy field, accounting for $29.44 \%$, and 641.69 hectares of dry land, accounting for $70.56 \%$. The cultivated land is mainly distributed in Shechong Township and Shapu town. Before the implementation of the project, the national natural quality of cultivated land is distributed in Grade 6, Grade 7, grade 9, grade 10 and grade 11. After the implementation of the project, the average grade of cultivated land in this area is $8.77,0.1$ higher than that before the construction. The national level utilization of cultivated land involved in the project is distributed in Grade 5, grade 6, Grade 7, Grade 8, grade 9 and grade 10. After the implementation of the project, the average national level utilization of cultivated land is $8.51,0.06$ higher than before the construction. The national economy of the cultivated land related to the project is concentrated in the range of grade 5 to grade 10, and the project is to be implemented. The average value of these categories is 8.43 , which is 0.14 higher than that before the construction.

\section{Discussion}

1) The significance of the study on the quality of cultivated land is significant [12] [13] [14]. This work plays a key role in both the quality and quantity of cultivated land, management and ecology; it can be used as a key guide for the permanent demarcation of basic farmland. Based on the basic farmland and other data, the responsibility of basic farmland protection is implemented, and the construction of basic farmland protection data base is completed [15]; it can be applied to the implementation and management of the overall land use planning, land development and reclamation, agricultural land productivity accounting and assessment of cultivated land protection responsibility objectives [16]. At the same time, the results of cultivated land quality updating can provide basic data support for the determination of cultivated land quality in the delimitation of basic farmland.

2) In 2016, there was no new cultivated land in county A of Guangxi, but there 
was a decrease in cultivated land. The main reason for the decrease in cultivated land was the construction occupation of urban, village, highway and facility agricultural land, of which urban occupation was the most. There are 909.46 hectares of cultivated land affected by the implementation of the project. After the implementation of the project, in addition to improving the national natural quality of cultivated land, the national utilization and national economy have also been improved to a certain extent.

3) Cultivated land in county A of Guangxi is mainly medium-sized land. Therefore, it is necessary to increase investment in land remediation, effectively implement relevant protection and quality construction work for new cultivated land, and significantly improve investment. We will focus on optimizing the field infrastructure and enhancing the basic land capacity, and enhance the investment and construction of the field infrastructure, comprehensively strengthen the quality construction of new cultivated land and the implementation of scientific fertilization, vigorously promote the production and application of organic fertilizer, straw recycling, green manure planting projects, and promote the overall improvement of the quality level of cultivated land [17] [18].

4) Relying on the ArcGIS platform, using the superposition method in the process of farmland quality evaluation, for data collection and editing, as well as the establishment of database and output of results, compared with the previous manual operation method, the workload is greatly reduced, the work efficiency is improved [19], and the results are more accurate.

5) Focusing on the cultivated land quality in 2016, this study focuses on the corresponding update and evaluation work with the help of ArcGIS. Based on the relevant data in 2015, through the superposition method and referring to the previous practice of agricultural land classification, with the help of GIS spatial analysis method, the data extraction and attribute assignment of new cultivated land, reduced cultivated land and quality construction cultivated land are completed, and the number of updates is calculated. According to the cultivated land map spots in the package, the cultivated land quality grade evaluation is carried out, which provides the basis for the later work of this update evaluation, and implements a more in-depth and comprehensive update of the cultivated land quality grade. In view of this update result, the corresponding evaluation database construction and other projects in 2016 are completed [20].

6) The evaluation of cultivated land quality in county A of Guangxi is a comprehensive evaluation based on the local cultivated land soil texture, cultivated soil layer thickness and other influencing factors, which accurately and objectively reflects the specific utilization status of cultivated land in this area, provides guidance for the optimization of the layout structure of this area, the improvement of cultivated land occupation and compensation balance measures, and provides guidance for land use planning and project scheme design. It provides basic data, and also lays a solid foundation for the next round of farmland quality evaluation [21] [22]. 


\section{Funding}

Subsidized by Guangxi Key Laboratory of Hidden Metallic Ore Deposits Exploration, Guilin University of Technology.

\section{Conflicts of Interest}

The authors declare no conflicts of interest regarding the publication of this paper.

\section{References}

[1] Yu, X.X. (2013) Policy Elaboration on Protecting Rural Cultivated Land. Jilin Agriculture, 4, 47.

[2] Cui, J. (2005) Study on the Grading and Evaluation of Agricultural Land and the Application of the Results. Anhui Agricultural University, Hefei.

[3] Wellis, W. and Tan, W.C. (2013) Analysis of Climate Change Characteristics in Liucheng County in Recent 50 Years. Agriculture and Technology, 33, 177-178.

[4] Cai, E.X., Zhou, X.W. and Jin, G. (2015) Study on Cultivated Land Grade Renewal in Land Consolidation Project Area Based on Factor Correction. Research on Soil and Water Conservation, 22, 147-150 + 157.

[5] Wang, L. (2015) Study on Cultivated Land Quality Upgrading Based on GIS. Chongqing Jiaotong University, Chongqing.

[6] Ministry of Land and Resources of the People's Republic of China (2003) Classification of Agricultural Land Quality (GB/T28407-2012). China Standard Press, Beijing.

[7] Cheng, F., Wang, H.B. and Yun, W.J. (2014) Investigation and Evaluation of Cultivated Land Quality Grades in China. China Land Science, 28, 75-82 + 97.

[8] Tong, L.Y. and Hu, S.G. (2015) Yang Leftover. Study on the Method of Farmland Quality Revaluation in Land Remediation Area. China Land Science, 29, 60-66 + 97

[9] Jing, Y.N. (2017) Quality Grading of New Cultivated Land. Agricultural Technology Services, 34, 149.

[10] Xu, J.C. (2010) Investigation and Evaluation of Cultivated Land Quality in China: Inner Mongolia Volume. China Earth Press, Beijing.

[11] Li, L.Q., Zhang, Q.P. and Zhong, J. (2015) Temporal and Spatial Variation Characteristics of Cultivated Land Quality at County Level. Western Resources, No. 6, 129-132.

[12] Xie, G.Y. (2017) Evaluation and Analysis of Cultivated Land Quality in 2014 in Nanxiong City. Zhongkai College of Agricultural Engineering, Guangzhou.

[13] Zhang, S.S. (2016) Study on the Evaluation of Cultivated Land Quality in Fengcheng City. Shenyang Normal University, Shenyang.

[14] Li, L.W. (2015) Quality Evaluation, Renewal and Spatial-Temporal Pattern Change Analysis of Cultivated Land in the County.

[15] Jin, J.J., Jiang, C. and Li, L. (2013) The Economic Valuation of Cultivated Land Protection: A Contingent Valuation Study in Wenling City, China. Landscape and Ur ban Planning, 119, 158-164. https://doi.org/10.1016/j.landurbplan.2013.06.010

[16] Song, K., Mu, H. and Song, S. (2019) Study on the Evaluation of Cultivated Land Quality in Huaiyin District, Jiangsu Province. Land and Resources Information, 5, 52-56.

[17] Zhang, C.H., Gao, S.G. and Li, W.F. (2018) Problems and Suggestions of Cultivated 
Land Quality in Zhoukou City. Agricultural Science and Technology Communication, No. 7, 19-21.

[18] Niu, C.H. (2018) Several Attempts to Monitor the Quality of Cultivated Land. Jilin Agriculture, No. 4, 72.

[19] Niu, X.R., Zhang, L.Q., Gong, J. and Liu, Q.Y. (2016) Evaluation of Cultivated Land Quality Based on GIS-Taking Yiling District of Yichang City as an Example. $\mathrm{Hu}^{-}$ bei Agricultural Science, 55, 1687-1690 + 1696.

[20] Lu, Y., Yang, L.K. and Zhou, Q.Q. (2016) Extraction of Update Data Package in Annual Update Evaluation of County-Level Cultivated Land Quality Based on GIS. Mapping and Spatial Geographic Information, 39, 135-137.

[21] Shao, J.A., Ge, X., Wei, C., et al. (2007) Classification and Gradation of Cultivated Land Quality in Bishan County of Chongqing, China. Chinese Geographical Science, 17, 82-91. https://doi.org/10.1007/s11769-007-0082-1

[22] Zhou, Y. and Wang, P.J. (2016) Study on Annual Renewal and Evaluation of Cultivated Land Quality in Boluo County. Modern Agricultural Science and Technology, 9, 195-196. 